\title{
Definition of Periprosthetic Joint Infection
}

\author{
Javad Parvizi, MD, FRCS \\ Rothman Institute, Thomas Jefferson University \\ Thorsten Gehrke, MD \\ Endo-Klinik Hamburg, Specialist Clinic for Bone and Joint Surgery, Hamburg, Germany
}

Follow this and additional works at: https://jdc.jefferson.edu/rothman_institute

Part of the Orthopedics Commons

Let us know how access to this document benefits you

\section{Recommended Citation}

Parvizi, MD, FRCS, Javad and Gehrke, MD, Thorsten, "Definition of Periprosthetic Joint Infection" (2014). Rothman Institute Faculty Papers. Paper 49.

https://jdc.jefferson.edu/rothman_institute/49

This Article is brought to you for free and open access by the Jefferson Digital Commons. The Jefferson Digital Commons is a service of Thomas Jefferson University's Center for Teaching and Learning (CTL). The Commons is a showcase for Jefferson books and journals, peer-reviewed scholarly publications, unique historical collections from the University archives, and teaching tools. The Jefferson Digital Commons allows researchers and interested readers anywhere in the world to learn about and keep up to date with Jefferson scholarship. This article has been accepted for inclusion in Rothman Institute Faculty Papers by an authorized administrator of the Jefferson Digital Commons. For more information, please contact: JeffersonDigitalCommons@jefferson.edu. 


\author{
As submitted to: \\ Journal of Arthroplasty \\ And later published as: \\ Definition of Periprosthetic Joint Infection \\ Volume 29, Issue, 7, pages:1331, July 2014 \\ doi: 10.1016/j.arth.2014.03.009
}

Javad Parvizi MD, FRCS ${ }^{1}$

Thorsten Gehrke MD ${ }^{2}$

The International Consensus Group on Periprosthetic Joint Infection

${ }^{1}$ The Rothman Institute at Thomas Jefferson University, Philadelphia, PA

${ }^{2}$ Endo-Klinik Hamburg, Specialist Clinic for Bone and Joint Surgery, Hamburg, Germany 


\section{To the Editor:}

Diagnosis of periprosthetic joint infection (PJI) remains challenging as no "gold standard" for diagnosis exists [3]. The challenge is then what test(s) or criterion (ia) can be used to define PJI. In an effort to standardize the definition of PJI, Musculoskeletal Infection Society (MSIS) convened a workgroup in 2011 to issue diagnostic criteria for PJI [1]. The MSIS definition of PJI consists of two major criteria, when the presence of either criterion would indicate PJI, and six minor criteria, when the presence of four or more would indicate PJI.

In August 2013 a large group of experts convened together in Philadelphia as part of an International Consensus Meeting on PJI. The consensus group, consisting of 400 experts from 52 countries and over 130 societies, met just ahead of the annual meeting of the MSIS. The consensus group endorsed the MSIS definition of PJI and modified the MSIS criteria slightly by adding the leukocyte esterase test as a minor criterion (Table 1). The document generated by the consensus group, including the diagnostic criteria for PJI, has been adopted by over 130 societies and organizations [2]. The diagnostic criteria introduced by the MSIS and modified by the International Consensus group has been adapted by the Center for Disease Control and will replace the previous definition of PJI that was used by the National Healthcare Safety Network (NHSN), surveillance arm of the CDC.

The consensus group also determined the acceptable threshold for the minor criteria, based on acuity of the infections (Table 2). The consensus group felt that there was no difference in the threshold for the minor criteria between total knee and total hip arthroplasties.

The consensus group also proposed an algorithmic approach to diagnosis of PJI that is based on the recommendations of the American Academy of Orthopedic Surgeons. 
It is hoped that the proposed diagnostic criteria will aid clinicians in their effort to diagnose and treat PJI. The availability of a standardized definition for PJI will allow a meaningful comparison of the medical literature reporting on issues related to PJI. It is abundantly clear that with the progress in molecular biology and in particular the biomarker science, a single test for diagnosis of PJI may indeed be within the reach of the medical community. 


\section{References}

1. Workgroup Convened by Musculoskeletal Infection Society. New definition for periprosthetic joint infection. J Arthroplasty Dec 2011;26(8):1136.

2. WwW.msis_na.org/consensus.

3. Della Valle C, Parvizi J, Bauer TW, et al. Diagnosis of periprosethtic joint infection of the hip and knee. J Bone Joint Surg Am 2011;93(14):1355 [20]. 